\title{
PERFORMANCE INVESTIGATION OF SMALL GAS TURBINE ENGINES TOPPED WITH WAVE ROTORS
}

\author{
Pezhman Akbari" \\ Michigan State University \\ Dept. of Mechanical Engineering \\ 2500 Engineering Building \\ East Lansing, Michigan 48824-1226 \\ Phone: (517) 4321102 \\ Fax: (347) 4127848 \\ Email: akbari@egr.msu.edu
}

\author{
Norbert Müller ${ }^{\dagger}$ \\ Michigan State University \\ Dept. of Mechanical Engineering \\ 2455 Engineering Building \\ East Lansing, Michigan 48824-1226 \\ Phone: (517) 4329139 \\ Fax: (347) 4127848 \\ Email: mueller@egr.msu.edu
}

\begin{abstract}
A performance analysis is performed for a small turbojet engine topped with various wave rotor cycles. Five different advantageous implementation cases for a four-port wave rotor into the given baseline engine are studied. The compressor and turbine pressure ratios, and the turbine inlet temperatures vary in the thermodynamic calculations according to the anticipated design objectives of the five considered cases. Advantages and disadvantages are outlined. Comparison between the theoretic performance results of wave-rotor-topped engines and the baseline engine shows a significant performance enhancement for almost all the cases studied. The highest gain is obtained for the case in which the topped engine operates with the same turbine pressure ratio, inlet temperature and the same physical compressor like that of the baseline engine. A general design map is generated showing the design space and optima for the baseline and topped engines.
\end{abstract}

\section{INTRODUCTION}

Gas turbines are typical power sources used in a wide size range for propulsion and power generation systems. Recently, there has been considerable interest in the research, development, and application of small gas turbines yielding high power density and enabling low-cost air vehicles. However, resulting from the smaller size, their efficiency and pressure ratio, hence specific work, are mostly lower than those of the large scale systems. Therefore, innovations are required to attractively enhance their performance.

At present, there are two major methods to enhance the performance of a simple cycle gas turbine: (1) improving the component efficiencies, especially of compressor and turbine, or (2) improving the thermodynamic process of the cycle by increasing

\footnotetext{
* Ph.D. Candidate, AIAA student member

${ }^{\dagger}$ Assistant Professor
}

turbine inlet temperatures. The aerodynamics of turbomachinery has already reached ${ }^{1}$ a very high level of component efficiencies up to around $90 \%$. Still improvements are possible, but further huge enhancements seem to be unlikely. From a thermodynamic point of view, increasing the turbine inlet temperature is the most efficient way to improve both the overall efficiency and specific power. However, the maximum temperature of the gas entering the turbine is limited by material considerations. Thus, a considerable jump in performance of small gas turbines can only be achieved by applying advanced thermodynamic processes that are not subjected to this limitation. Topping a gas turbine with a wave rotor is an appropriate solution. The turbine inlet temperature may stay the same while the combustion takes place at a higher temperature. Even, the turbine inlet temperature may be lowered. A pressure gain additional to that provided by the compressor is also obtained by the wave rotor. Therefore, the performance enhancement is achieved by increasing mostly both the overall efficiency and specific power, hence reducing the specific fuel consumption considerably. This occurs to be especially effective in the range of smaller gas turbines often used for propulsion of small vehicles or for distributed power generations.

\section{HISTORY OF WAVE ROTORS}

The idea of using a wave-rotor topping cycle has been first proposed by Claude Seippel of Brown Boveri Company (BBC) in Switzerland in 1942. ${ }^{2-4}$ Now BBC is Asea Brown Boveri (ABB) and its pressure wave supercharger termed as the Comprex ${ }^{\circledR}$ has been used commercially for passenger car and heavy diesel engines. ${ }^{5,6}$

Since the early 1960s the General Electric Company (GE), General Power Corporation (GPC), and Rolls Royce were involved in the development of a prototype wave rotor for propulsion applications. ${ }^{7,8}$ Mathematical Science Northwest also studied various aspects of wave energy exchange and proposed a wave rotor design for aircraft turbofan engines. ${ }^{7}$ In the 1980 s different U.S. 
agencies like DARPA (Defense Advanced Research Program Projects Agency) and the U.S. Navy expressed interest and sponsored programs to develop an understanding of wave rotor science and technology. Many developments were presented in the 1985 ONR/NAVAIR Wave Rotor Research and Technology Workshop. ${ }^{8}$

Interest in wave rotor technology has again increased recently. Since the 1990s, a large research program at NASA Glenn Research Center (GRC) collaborated by the U.S. Army Research Laboratory (ARL) and RollsRoyce Allison has initiated to develop and demonstrate the benefits of the wave rotor technology, which will be useful in future aircraft propulsion designs. ${ }^{9-16}$ An excellent overview has been provided by Welch. ${ }^{17}$

In 1993, using a thermodynamic approach to calculate the thermal efficiency and specific power, Wilson and Paxson ${ }^{18}$ published a feasibility study for topping jet engines with a wave rotor. Applied to the case of an aircraft flying at Mach 0.8 , they have shown that a wave-rotor topped engine may gain $1 \ldots 2 \%$ in efficiency and $10 \ldots 16 \%$ in specific power compared to a simple jet engine with the same overall pressure ratio and turbine inlet temperature. Paxson also has developed a one-dimensional design model to calculate off-design wave rotor performance ${ }^{19}$ and has verified it using experimental data. The model solves the unsteady viscous flow field in an axial passage for time-constant inlet and outlet port conditions, while accounting for losses due to gradual passage opening and closing, viscous and heat transfer effects, leakage, and nonuniform port flow field mixing. Recent improvement and validations have completed it as a preliminary and general design tool. However, simpler computational tools would be beneficial for wide industrial use.

In 1995, Welch et al. ${ }^{20}$ have predicted a $19 \ldots 21 \%$ increase in specific power and a $16 \ldots 17 \%$ decrease in specific fuel consumption compared with the baseline engines in performance calculations for small (300 to $500 \mathrm{~kW}$ ) and intermediate (2000 to $3000 \mathrm{~kW}$ ) waverotor-enhanced turboshaft engines. Same calculations for a wave-rotor-enhanced large turbofan engine, equal in thrust to the baseline engine, have shown a $6 \ldots 7 \%$ reduction in thrust specific fuel consumption. Welch also has established one-dimensional and a twodimensional analysis models to estimate the performance enhancements of wave rotors. ${ }^{13,14,21-23}$

In 1996, Snyder and Fish 17, 24, 25 have evaluated the Rolls-Royce Allison 250 turboshaft engine as a potential platform for a wave rotor demonstration, predicting a $18 . . .20 \%$ increase in specific power and a $15 \ldots 22 \%$ decrease in specific fuel consumption. They have used a detailed map of the wave rotor cycle performance accomplished by Wilson and Paxson. ${ }^{16-18}$

After numerical modeling 26, 27 in 1999, Fatsis and Ribaud from the French National Aerospace Research Establishment (ONERA) have performed ${ }^{28}$ a basic investigation of the thermodynamic performance enhancement for various types of gas turbines topped with wave rotors, including auxiliary power units, turboshaft, turbojet, turbofan engines. The variation of wave-rotor compression and expansion efficiency, as well as mixing and pressure losses in the ducting, have been taken into account. For such as turboshaft engines and auxiliary power units, the results have shown the largest gains in power and largest reduction of specific fuel consumption for engines with a low compressor pressure ratio and high turbine inlet temperature. These results are consistent with those obtained by Jones and Welch ${ }^{29}$ for the wave-rotor topping of turboshaft, highbypass turbofan, auxiliary power, and ground based power engines.

In a recent study 30,31 , the authors have performed a thermodynamic analysis to calculate the thermal efficiency and specific work of two small gas turbines (30 and $60 \mathrm{~kW}$ ) topped with a four-port wave rotor. The results obtained predict that for the $30 \mathrm{~kW}$ engine, with a compressor pressure ratio of 3.6, the overall efficiency and specific work can be increased by approximately $33 \%$ if the engine is topped by a wave rotor with a compression ratio of 1.8 . The general performance maps obtained by the authors clearly have demonstrated the performance enhancements through the use of wave rotors for ground based gas turbines.

The current work presents a comprehensive and systematic performance analysis of a small turbojet engine topped by a four-port wave rotor in various ways. While the performance evaluation of several gas turbine engines has been studied extensively ${ }^{8,17}$, to the knowledge of the authors, there exits no comprehensive work investigating potential benefits of various implementation cases of wave rotor topping cycles for small gas turbines. In contrast to using existing performance computational tools, the presented results were obtained using basic thermodynamic equations along with the wave-rotor characteristic equation. ${ }^{18}$ The model can be employed to predict the performance improvement of various wave-rotor topping cycles without the need of knowing the details of the complex fluid mechanics within the wave rotor. The challenges and advantages associated with the different implementation cases are discussed further below. 


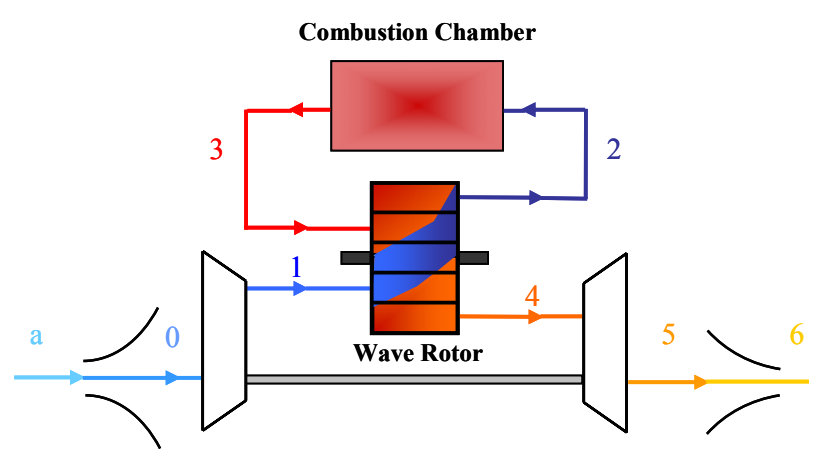

Figure 1: A schematic of a turbojet engine topped by a four-port wave rotor

\section{WAVE ROTOR DESCRIPTION}

In a conventional arrangement, a wave rotor is embedded between the compressor and turbine "parallel" to the combustion chamber. Figure 1 illustrates how a four-port wave rotor is used to top a turbojet engine. Point "a" refers to the ambient condition at the inlet. Detailed descriptions of such a wave rotor are provided in the references cited above.

In the wave rotor channels, the hot gas leaving the combustion chamber compresses the air coming out of the compressor. This means that wave rotors utilize a high-pressure fluid to transfer its energy directly to a low-pressure fluid. After the additional compression of the air in the wave rotor, it is discharged into the combustion chamber. The burned gas pre-expands during the compression of the air and is afterwards scavenged toward the turbine. Then, the channels are re-connected to the compressor outlet, allowing fresh pre-compressed air to flow into the wave rotor channels. Due to the expansion in the wave rotor, the pre-expanded gas can enter the turbine with the same (or lower) temperature as the gas would have in a conventional arrangement without the wave rotor. However, the gas pressure is higher than the compressor exit pressure by the pressure gain obtained in the wave rotor. This is in contrast to the untopped engine, where - by the pressure loss occurring in the combustion chamber - the turbine inlet pressure is lower than the compressor discharge pressure.

The general advantage of using a wave rotor becomes apparent when comparing the thermodynamic cycles of baseline and wave-rotor-enhanced engines. Figure 2 shows a schematic temperature-entropy diagram of a turbojet baseline engine and the corresponding waverotor-topped engine. The shown case is the one most

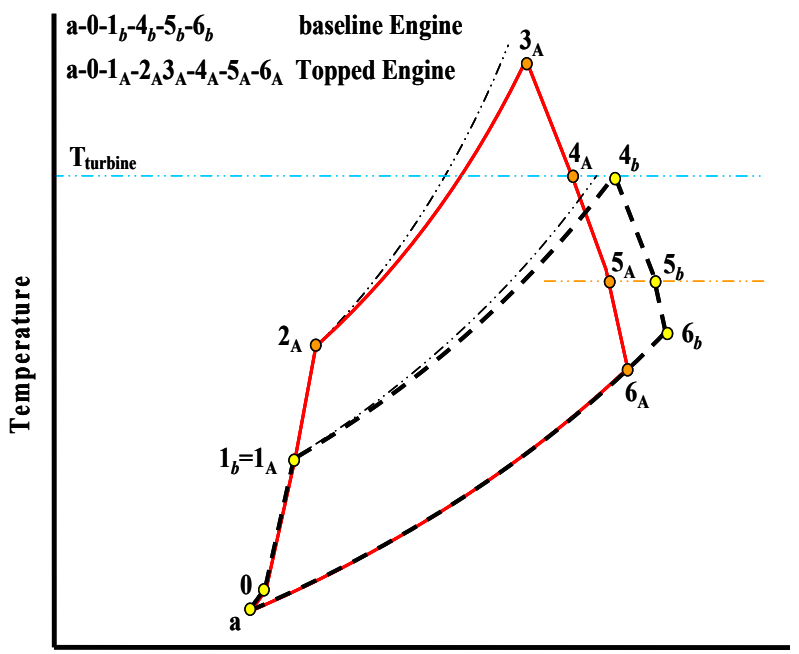

Entropy

Figure 2: Schematic Temperature-Entropy diagram for a turbojet baseline engine and the most common implementation case of a topping wave-rotor

commonly discussed in references and in this paper is referred to as Case A. It is evident that both gas turbines are operating with the same turbine inlet temperature and compressor pressure ratio. All wave rotors considered in this work each have zero shaft work. Therefore, the wave rotor compression work is equal to the wave rotor expansion work. Thus, the energy increase from point " $l_{b}$ " to " 4 " in the baseline engine and from point " $1_{\mathrm{A}}$ " to " $4_{\mathrm{A}}$ " in the wave-rotor-topped engine is the same. This results in the same heat addition for both cycles. However, the thrust of the topped engine is higher than that of the baseline engine, due to the pressure gain across the wave rotor $\left(p_{t 4 \mathrm{~A}}>p_{t 4 b}\right.$ , where index " $t$ " indicates total values). Therefore, the overall efficiency for the topped engine is higher than that of the baseline engine. The inherent gas dynamic design of the wave rotor compensates for the combustor pressure loss from point " $2_{\mathrm{A}}$ " to " $3_{\mathrm{A}}$ ". So, the compressed air leaving the wave rotor at point " $2_{\mathrm{A}}$ " is at higher pressure than the hot gas entering the wave rotor at point " $3 \mathrm{~A}$ ". 32

\section{THERMODYNAMIC CALCULATIONS}

To evaluate the performance enhancement of topping turbojet engines with wave rotors, a thermodynamic approach is used calculating the theoretic performance of wave-rotor-topped and baseline engines. The methodology is similar to the one introduced by Wilson and Paxson ${ }^{18}$ with some modifications. 


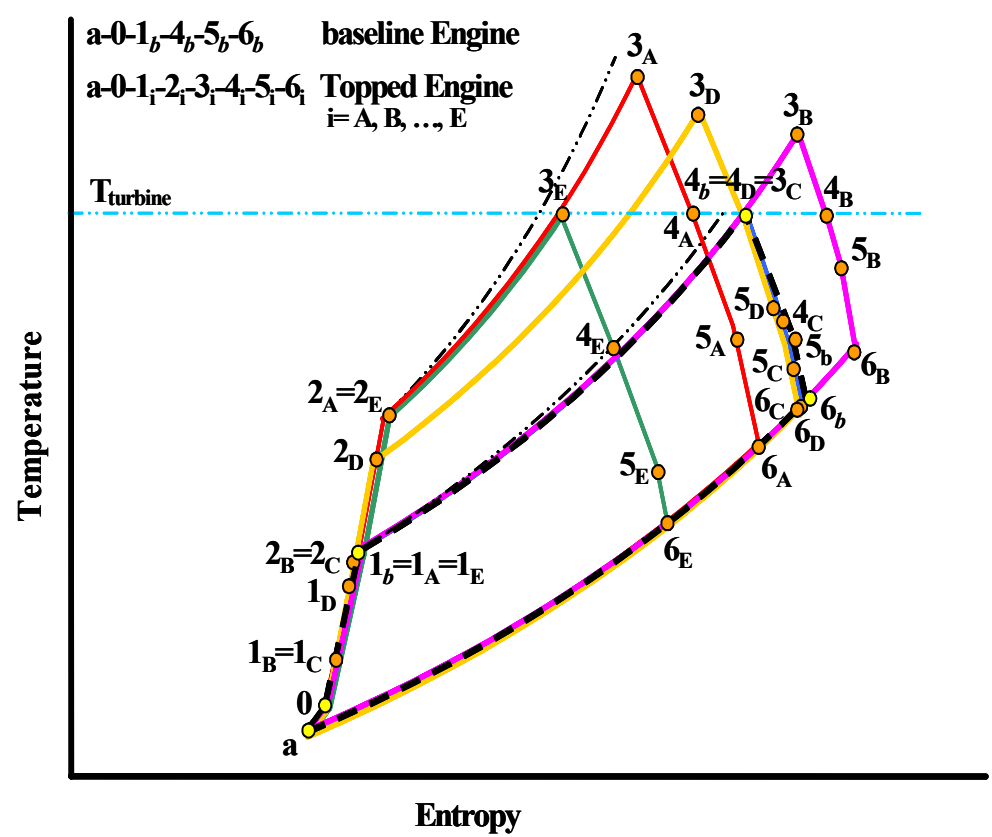

Figure 3: Schematic Temperature-Entropy diagram for a baseline cycle and five different wave-rotor-topped cycles

\section{IMPLEMENTATION CASES}

There are several possibilities to top a gas turbine with a wave rotor. Nonetheless, knowing about possible design restrictions and preferences, mainly five different advantageous implementation cases for a wave rotor into a given baseline engine can be introduced as the following:

Case A: same compressor, same turbine inlet temperature

Case B: same overall pressure ratio, same turbine inlet temperature

Case C: same combustor

Case D: same turbine inlet pressure, same turbine inlet temperature

Case E: same compressor, same combustion end temperature

Figure 3 visualizes all five cases in a schematic T-s diagram. Path a- $0-1_{b}-4_{b}-5_{b}-6_{b}$ represents the baseline cycle and $\mathrm{a}-0-1_{\mathrm{i}}-2_{\mathrm{i}}-3_{\mathrm{i}}-4_{\mathrm{i}}-5_{\mathrm{i}}-6_{\mathrm{i}}(\mathrm{i}=\mathrm{A}, \mathrm{B}, \ldots, \mathrm{E})$ indicates the wave-rotor-topped cycles, where the indices indicate the case. One of the five cases might be preferable for a practical design. However intermediate design cases are possible.

Case A: In Case A $\left(a-0-1_{A}-2_{A}-3_{A}-4_{A}-5_{A}-6_{A}\right)$ the pressure ratio of the compressor is kept unchanged, so the physical compressor of the baseline engine can also be used for the wave-rotor-enhanced engine provided the mass flow is kept approximately the same. The pressure in the combustion chamber of the enhanced engine is increased by the compression ratio of the wave rotor. This may require modifications to the structure of the combustion chamber and to the fuel injection system. The heat addition in the combustor is the same as for the baseline engine, but it takes place after the energy exchange in the wave rotor, hence starting at higher temperature. Thus, the combustion end temperature is higher than that of the baseline engine possibly requiring additionally a thermal enhancement of the combustor structure. The turbine inlet temperature is kept the same as for the baseline engine. Thus, the turbine pressure ratio is the same for both engines, since the compressor is unchanged. However, due to the higher turbine inlet pressure, the turbine inlet volume flow is less, which may require an adaptation of the turbine. This implementation case is one of the most beneficial implementation cases.

Case B: In Case B (a- $\left.0-1_{B}-2_{B}-3_{B}-4_{B}-5_{B}-6_{B}\right)$ the overall pressure ratio for the wave-rotor-enhanced engine is kept equal to that of the baseline engine. Therefore, the combustor works under the same pressure. However, the heat addition in the combustor for the wave-rotortopped engine is higher by the amount of the waverotor expansion work. This results in a higher combustion end temperature and may require some adaptation of the combustor. The turbine and compressor work with a lower pressure ratio. Thus both may be adapted to benefit most. This might reduce the cost of the compressor and turbine due to reduction of stages in case multi-stage (mostly axial) types are used or due to reduction of the tip diameter in case radial (mostly single-stage) types are used. With a smaller tip diameter the wheels can be manufactured more economically in shorter time from cheaper materials with less strength and on smaller machines. Beside an increased thrust, this case additionally provides the highest turbine outlet temperature of all five cases investigated. The temperature of the leaving exhaust 
gas $\left(T_{6 B}\right)$ is considerably higher than that of the baseline engine. Therefore, this case may be especially attractive if heat recovery is anticipated.

Case C: Case $\mathrm{C}\left(\mathrm{a}-0-1_{\mathrm{C}}-2_{\mathrm{C}}-3_{\mathrm{C}}-4_{\mathrm{C}}-5_{\mathrm{C}}-6_{\mathrm{C}}\right)$ assumes that it is desirable for the wave-rotor-enhanced engine to use the unmodified combustor of the baseline engine. So the overall pressure ratio for the wave-rotor-enhanced engine is kept equal to that of the baseline engine, as is the combustor inlet and outlet temperature. The heat addition in the combustor is consequently the same The implementation of the wave rotor considerably reduces the pressure ratios of the turbine and compressor. In addition, the turbine inlet temperature is lower than that of the baseline engine. Thus, the turbine and compressor could be made of less thermal resistant material and as discussed in Case B they also could be smaller and hence less expensive. This might be the main implementation reason since the performance enhancement is nearly negligible for the engine considered in this study.

Case D: Case D (a- $\left.0-1_{D}-2_{D}-3_{D}-4_{D}-5_{D}-6_{D}\right)$ uses the same turbine inlet temperature and inlet pressure of the baseline engine. The pressure in the combustion chamber and the combustion end temperature are higher than those of the baseline engine, but lower than those of Case A. Thus, less effort might be required to adapt the structure and fuel injection of the combustion chamber. Due to the wave-rotor-topping, the compressor needs to produce less pressure ratio than that of the baseline engine and in turn the turbine pressure ratio is less, too. This may allow for a smaller and less expensive compressor and turbine as discussed for Case B and C. Resulting from the lower pressure ratio in the compressor, hence lower compressor discharge temperature, the heat addition in the combustor has to be more than that of the baseline engine to utilize the same allowed turbine inlet temperature. The results shown later indicate that this case gives the second highest specific thrust increase for the topped engine.

Case E: Case $5\left(\mathrm{a}-0-1_{\mathrm{E}}-2_{\mathrm{E}}-3_{\mathrm{E}}-4_{\mathrm{E}}-5_{\mathrm{E}}-6_{\mathrm{E}}\right)$ is similar to Case $\mathrm{A}$, but the combustion end temperature (the maximum cycle temperature) is restricted to the turbine inlet temperature of the baseline engine in order to not impose additional thermal requirements for the combustor. The overall pressure ratio is the same as in Case A and greater than (by the wave rotor pressure ratio) that of the baseline engine. The heat addition in the combustor is less than that of the baseline engine due to the wave-rotor compression work added to the fluid before the combustion. The compressor is the same physical compressor as for the baseline engine.

\footnotetext{
\$ The wave rotor compression efficiency is greater than the compressor efficiency. Therefore, the combustor inlet temperature is in fact negligibly less and hence the heat addition is negligibly more than that in the baseline engine.
}

Table 1: Baseline engine data, assuming, $C p_{\text {air }}=1.005 \mathrm{~kJ} / \mathrm{kgK}, C p_{\text {gas }}=1.148 \mathrm{~kJ} / \mathrm{kgK}, \gamma_{\text {air }}=1.4, \gamma_{\text {gas }}=1.33$

\begin{tabular}{|l|c|c|}
\hline \multicolumn{3}{|c|}{ Baseline engine } \\
\hline Turbine inlet temperature & $T_{4 b}$ & $1116.5 \mathrm{~K}$ \\
\hline Compressor pressure ratio & $p_{I b /} p_{0}$ & 3.6 \\
\hline Diffuser isentropic efficiency & $\eta_{D}$ & $93 \%$ \\
\hline Compressor isentropic efficiency & $\eta_{C}$ & $80 \%$ \\
\hline Compressor polytropic efficiency & $\eta_{P C}$ & $83 \%$ \\
\hline Combustion efficiency & $\eta_{Q}$ & $98 \%$ \\
\hline Combustor pressure ratio & $\Pi_{c o m b}$ & 0.95 \\
\hline Mechanical transmission efficiency & $\eta_{M}$ & $99 \%$ \\
\hline Turbine isentropic efficiency & $\eta_{T}$ & $84 \%$ \\
\hline Turbine polytropic efficiency & $\eta_{P T}$ & $83 \%$ \\
\hline Nozzle isentropic efficiency & $\eta_{N}$ & $95 \%$ \\
\hline
\end{tabular}

However the turbine in the topped cycle works with a little higher pressure ratio than that of the baseline engine since the turbine inlet temperature is less than that of the baseline engine. In fact, it is the lowest of all cases investigated. This may give the option to produce the turbine wheel at lower costs out of less thermal resistant material.

For thermodynamic calculations, a reasonable case considered here is an aircraft equipped with a simple turbojet engine (no afterburner installed) flying at an altitude of $10,000 \mathrm{~m}$ at Mach 0.8 . The component performance parameters at the baseline design points are listed in Table 1. It is assumed that the compressor inlet condition is the same for both baseline and waverotor-enhanced engines. Considering the same "aerodynamic quality" of the wheels, the polytropic efficiencies of the compressor and turbine are kept the same for both enhanced and baseline engines. Ambient air is entering the inlet diffuser at $T_{a}=223 \mathrm{~K}$. The maximum allowable turbine inlet temperature is set to $T_{t 4} \leq 1116.5 \mathrm{~K}$. According to previous wave rotor investigations ${ }^{18,23,28}$ the wave rotor compression and expansion efficiencies are assumed with $\eta_{W C}=\eta_{W E}=0.83$. A wave rotor compression ratio of $P R_{W}=p_{t 2} / p_{t 1}=1.8$ appears to be conceivable for the envisioned application and is chosen for the discussion of representative values. However, in this work the plots are shown for various wave rotor pressure ratios indicating its effect on the performance enhancement.

\section{ANALYTICAL PROCEDURE}

According to Fig. 1, the following steps are followed to calculate the thermodynamic properties of the gases in different states of the topped cycle:

Path a-0: With the given flight Mach number $M$, the stagnation temperature across the diffuser $\left(T_{t a}=T_{t 0}\right)$ is calculated by:

5 


$$
T_{t 0}=T_{t a}=T_{a}\left(1+\frac{\gamma_{\text {air }}-1}{2} M^{2}\right)
$$

Using the definition of the diffuser isentropic efficiency $\left(\eta_{D}\right)$, the diffuser outlet total pressure is obtained from:

$$
\frac{p_{t 0}}{p_{a}}=\left(1+\eta_{D} \frac{u_{a}{ }^{2}}{2 C p_{\text {air }} T_{a}}\right)^{\gamma_{\text {air }} / \gamma_{\text {air }}-1}
$$

Path 0-1: The compressor outlet total temperature and pressure are calculated by:

$$
\begin{gathered}
T_{t 1}=T_{t 0}+\frac{T_{t 0}}{\eta_{C}}\left(R^{\frac{\gamma_{a i r}-1}{\gamma_{a i r}}}-1\right) \\
\frac{p_{t 1}}{p_{a}}=\frac{p_{t 1}}{p_{t 0}} \frac{p_{t 0}}{p_{a}}=R \cdot \frac{p_{t 0}}{p_{a}}
\end{gathered}
$$

where the compressor isentropic efficiency $\left(\eta_{C}\right)$ relates the compressor pressure ratio $(R)$ to the compressor polytropic efficiency $\left(\eta_{P C}\right)$ through:

$$
\eta_{C}=\frac{R^{\frac{\gamma_{a i r}-1}{\gamma_{a i r}}}-1}{R^{\frac{\gamma_{a i r}-1}{\gamma_{\text {air }} \eta_{P C}}}-1}
$$

For Cases $\mathrm{A}$ and $\mathrm{E}$, the compressor pressure ratio is equal to that of the baseline engine $(R=3.6)$. However, for Cases $\mathrm{B}$ and $\mathrm{C}$ its value is calculated by dividing the baseline compressor pressure ratio with the wave rotor compression ratio $P R_{W}$. For Case $\mathrm{E}$, the value of $R$ is calculated in a way that keeps the pressure at turbine inlet equal for both baseline and topped engines. It can be performed by reverse solving of equations 3-22.

Path 1-2: The flow properties after the wave rotor compression process are obtained by:

$$
\begin{gathered}
T_{t 2}=T_{t 1}+\frac{T_{t 1}}{\eta_{W C}}\left(P R_{W}^{\frac{\gamma_{\text {air }}-1}{\gamma_{\text {air }}}}-1\right) \\
\frac{p_{t 2}}{p_{a}}=\frac{p_{t 2}}{p_{t 1}} \frac{p_{t 1}}{p_{a}}=P R_{W} \cdot R \cdot \frac{p_{t 0}}{p_{a}}
\end{gathered}
$$

Path 2-3: The fuel/air ratio $\left(f=m_{f} / m_{\text {air }}\right)$ can be obtained by applying the energy equation to the combustion chamber as:

$$
\eta_{Q} f h_{P R}=(1+f) C p_{\text {gas }} T_{t 3}-C p_{\text {air }} T_{t 2}
$$

where $h_{P R}$ is the heating value of the fuel. The value of $43000 \mathrm{~kJ} / \mathrm{kg}$ will be used for all calculations here. This equation gives $f$ as:

$$
f=\frac{C p_{g a s} T_{t 3}-C p_{a i r} T_{t 2}}{\eta_{Q} h_{P R}-C p_{g a s} T_{t 3}}
$$

Alternatively, $f$ can be expressed based on the turbine total inlet temperature $\left(T_{t 4}\right)$ and the compressor total exit temperature $\left(T_{t 1}\right)$. For this purpose, wave rotor compression and expansion specific works are defined respectively as follows:

$$
\begin{gathered}
w_{W C}=C p_{\text {air }}\left(T_{t 2}-T_{t 1}\right) \\
w_{W E}=(1+f) C p_{\text {gas }}\left(T_{t 3}-T_{t 4}\right)
\end{gathered}
$$

Here, it is justified that $\dot{m}_{1}=\dot{m}_{2}=\dot{m}_{\text {air }}$ and $\dot{m}_{3}=\dot{m}_{4}=\dot{m}_{\text {air }}+\dot{m}_{f}$ (generally, the mass flow rates $\dot{m}_{1}$ and $\dot{m}_{2}$ are not quite the same. Similarly, mass flow rates $\dot{m}_{3}$ and $\dot{m}_{4}$ are not equal either). Now, Eq. (8) can be expressed as:

$\eta_{Q} f h_{P R}=(1+f) C p_{\text {gas }} T_{t 4}+w_{W E}-w_{W C}-C p_{\text {air }} T_{t 1}$

since the net output work of the wave rotor is zero $\left(w_{W C}=w_{W E}\right)$, solving for $f$ leads to:

$$
f=\frac{C p_{\text {gas }} T_{t 4}-C p_{\text {air }} T_{t 1}}{\eta_{Q} h_{P R}-C p_{\text {gas }} T_{t 4}}
$$

For Cases $\mathrm{C}$ and $\mathrm{E}$ where $T_{t 3}$ is equal to the baseline inlet turbine temperature, Eq. (9) is used to calculate $f$. For Cases $\mathrm{A}, \mathrm{B}$, and $\mathrm{D}$ where $T_{t 4}$ is a known value and is equal to the baseline inlet turbine temperature, $f$ can be obtained by using Eq. (13). The relation between $T_{t 3}$ and $T_{t 4}$ can be found by equating Eq. (10) with (11):

$$
T_{t 3}=T_{t 4}+\left[\frac{T_{t 1}}{\eta_{W C}}\left(P R_{W}^{\frac{\gamma_{\text {air }}-1}{\gamma_{\text {air }}}}-1\right)\right] \frac{C p_{\text {air }}}{(1+f) C p_{\text {gas }}}
$$

Finally, the total pressure after the combustion chamber is obtained by:

$$
\frac{p_{t 3}}{p_{a}}=\frac{p_{t 3}}{p_{t 2}} \frac{p_{t 2}}{p_{a}}=\Pi_{c o m b} \cdot P R_{W} \cdot R \cdot \frac{p_{t 0}}{p_{a}}
$$

Path 3-4: To obtain the turbine inlet total pressure $\left(p_{t 4}\right)$, it is convenient to express the wave rotor compression and expansion works in terms of pressure ratios as follows:

$$
\begin{aligned}
& \dot{W}_{W C}=\dot{m}_{\text {air }} C p_{\text {air }}\left(T_{t 2}-T_{t 1}\right)=\frac{\dot{m}_{\text {air }} C p_{\text {air }}}{\eta_{W C}}\left(P R_{W}^{\frac{\gamma_{\text {air }}-1}{\gamma_{\text {air }}}}-1\right) \\
& \dot{W}_{W E}=\left(\dot{m}_{\text {air }}+\dot{m}_{f}\right) C p_{\text {gas }}\left(T_{t 3}-T_{t 4}\right) \\
& =\left(\dot{m}_{\text {air }}+\dot{m}_{f}\right) C p_{\text {gas }} \eta_{W E} T_{t 3}\left[1-\left(\frac{P O}{\eta_{\text {comb }} P R_{W}}\right)^{\gamma_{\text {gas }}-1 / \gamma_{\text {gas }}}\right]
\end{aligned}
$$


where $P O=p_{t 4} / p_{t 1}$ is the gain pressure ratio across the wave rotor. Equating the compression work to the expansion work leads to:

$$
\begin{aligned}
& \frac{C p_{\text {air }} T_{t 1}}{\eta_{W C}}\left(P R_{W} \frac{\gamma_{\text {air }}-1}{\gamma_{\text {air }}}-1\right)= \\
&(1+f) C p_{\text {gas }} \eta_{W E} T_{t 3}\left[1-\left(\frac{P O}{\eta_{\text {comb }} P R_{W}}\right)^{\gamma_{\text {gas }}-1 / \gamma_{\text {gas }}}\right]
\end{aligned}
$$

Substituting $T_{t 3}$ from Eq. (14) in the above equation and some algebra gives:

$$
P O=\Pi_{c o m b} P R_{W}\left\{1-\frac{A \frac{1}{\eta_{W E} \eta_{W C}} B}{1+A \frac{1}{\eta_{W C}} B}\right\}^{\gamma_{g a s} / \gamma_{\text {gas }}-1}
$$

where

$$
\begin{gathered}
A=\frac{C p_{\text {air }}}{(1+f) C p_{\text {gas }}} \\
B=\frac{T_{t 1}}{T_{t 4}}\left[P R_{W}\left(\gamma_{\text {air }}-1\right) / \gamma_{\text {air }}-1\right]
\end{gathered}
$$

Equation (19) is a modified version of the "wave-rotor characteristic" equation introduced in the literature. This equation represents the performance of the wave rotor. By using Eq. (19), the turbine inlet total pressure is obtained by:

$$
\frac{p_{t 4}}{p_{a}}=\frac{p_{t 4}}{p_{t 1}} \frac{p_{t 1}}{p_{a}}=P O \cdot R \cdot \frac{p_{t 0}}{p_{a}}
$$

Path 4-5: In turbojet engines, by considering the mechanical transmission efficiency, the compressor shaft work equals the turbine output work:

$$
C p_{\text {air }}\left(T_{t 1}-T_{t 0}\right)=\eta_{M}(1+f) C p_{\text {gas }}\left(T_{t 4}-T_{t 5}\right)
$$

Therefore, the total temperature of the gas leaving the turbine can be calculated as:

$$
T_{t 5}=T_{t 4}-\frac{C p_{a i r}\left(T_{t 1}-T_{t 0}\right)}{\eta_{M}(1+f) C p_{\text {gas }}}
$$

To find the total pressure of the gas leaving the turbine $\left(p_{t 5}\right)$, the value of the turbine isentropic efficiency $\left(\eta_{T}\right)$ is needed. There are two ways to calculate $\eta_{T}$ for a turbine:

$$
\eta_{T}=\frac{\left(\frac{p_{t 5}}{p_{t 4}}\right)^{\left(\gamma_{\text {gas }}-1\right) \eta_{P T} / \gamma_{\text {gas }}}-1}{\left(\frac{p_{t 5}}{p_{t 4}}\right)^{\left(\gamma_{\text {gas }}-1\right) / \gamma_{\text {gas }}}-1}
$$

and

$$
\eta_{T}=\frac{\left(\frac{T_{t 5}}{T_{t 4}}\right)-1}{\left(\frac{p_{t 5}}{p_{t 4}}\right)^{\gamma_{g a s}-1 / \gamma_{g a s}}-1}
$$

It is preferred to use the turbine polytropic efficiency $\eta_{P T}$ to obtain $p_{t 5}$. Therefore, by equating the above two equations:

$$
\frac{p_{t 5}}{p_{t 4}}=\left(\frac{T_{t 5}}{T_{t 4}}\right)^{\frac{\gamma_{g a s}}{\left(\gamma_{g a s}-1\right) \eta_{P T}}}
$$

or,

$$
\frac{p_{t 5}}{p_{a}}=\frac{p_{t 4}}{p_{a}}\left(\frac{T_{t 5}}{T_{t 4}}\right)^{\frac{\gamma_{g a s}}{\left(\gamma_{g a s}-1\right) \eta_{P T}}}
$$

Path 5-6: For a given local pressure ratio at the nozzle exit $\left(p_{6} / p_{a}\right)$, it is true that:

$$
\frac{p_{t 5}}{p_{6}}=\frac{p_{t 4}}{p_{a}} \frac{p_{t 5}}{p_{t 4}} \frac{p_{a}}{p_{6}}=\frac{p_{t 4}}{p_{a}} \frac{p_{t 5} / p_{a}}{p_{t 4} / p_{a}} \frac{1}{p_{6} / p_{a}}
$$

Parameter $p_{t 5} / p_{6}$ is a useful term to calculate the local gas temperature leaving the nozzle $\left(T_{6}\right)$ by using the definition of the nozzle isentropic efficiency $\left(\eta_{N}\right)$ :

$$
T_{6}=T_{t 5}-\eta_{N} T_{t 5}\left[1-\left(\frac{1}{p_{t 5} / p_{6}}\right)^{\frac{\gamma_{g a s}-1}{\gamma_{g a s}}}\right]
$$

Since $T_{t 5}=T_{t 6}$, the nozzle exit velocity $\left(u_{6}\right)$ can be calculated from:

$$
u_{6}=\sqrt{2 C p_{\text {gas }}\left(T_{t 5}-T_{6}\right)}
$$

Therefore, the nozzle exit Mach number is obtained by:

$$
M_{6}=\frac{u_{6}}{\sqrt{\gamma_{\text {gas }} R_{\text {gas }} T_{6}}}
$$

Finally, for the given $p_{6} / p_{a}$, the ratio of $p_{t \sigma} / p_{a}$ is calculated by:

$$
\frac{p_{t 6}}{p_{a}}=\frac{p_{t 6}}{p_{6}} \frac{p_{6}}{p_{a}}=\left(1+\frac{\gamma_{\text {gas }}-1}{2} M_{6}{ }^{2}\right)^{\frac{\gamma_{\text {gas }}}{\gamma_{\text {gas }}-1}} \frac{p_{6}}{p_{a}}
$$

After calculating the thermodynamic properties of all states in the cycle, it is possible to calculate the engine performance parameters.

The thrust produced by the engine is:

$$
T=\left(\dot{m}_{\text {air }}+\dot{m}_{f}\right) u_{6}-\dot{m}_{\text {air }} u_{a}+\left(p_{6}-p_{a}\right) A_{N}
$$


where $A_{N}$ is the exhaust area of the nozzle. The pressure term $\left(p_{6}-p_{a}\right) A_{N}$ is not zero only if the exhaust jet is supersonic. The specific thrust (thrust per unit mass flow of air) can be written as:

$$
S T=(1+f) u_{6}-u_{a}+\left(p_{6}-p_{a}\right) \frac{A_{N}}{\dot{m}_{\text {air }}}
$$

The pressure term can be presented ${ }^{33}$ as:

$$
\left(p_{6}-p_{a}\right) \frac{A_{N}}{\dot{m}_{\text {air }}}=a_{a}\left[(1+f) \frac{R_{\text {gas }}}{R_{\text {air }}} \frac{T_{6} / T_{a}}{u_{6} / a_{a}} \frac{1-p_{a} / p_{6}}{\gamma_{\text {air }}}\right]
$$

where $a_{a}$ is the sound velocity of the entering air. Therefore, the specific thrust can be shown as:

$$
S T=(1+f) u_{6}-u_{a}+a_{a}\left[(1+f) \frac{R_{\text {gas }}}{R_{\text {air }}} \frac{T_{6} / T_{a}}{u_{6} / a_{a}} \frac{1-p_{a} / p_{6}}{\gamma_{\text {air }}}\right]
$$

Thus, the specific fuel consumption $(S F C)$ can be simply obtained as:

$$
S F C=\frac{f}{S T}
$$

Finally, the overall efficiency can be calculated by:

$$
\eta_{O}=\frac{S T u_{a}}{f h_{P R}}
$$

\section{PREDICTED PERFORMANCE RESULTS}

Case $\mathrm{A}$ is the most common case discussed in the literature and it gives mostly the best performance enhancement. Therefore it is discussed here in more detail. Figure 4 illustrates the increases of cycle overall efficiency (dash point) and specific thrust (dashed), and the decrease of specific fuel consumption (solid) with increases of values of the wave rotor pressure ratio $P R_{W}$. The plot visualizes how the effect develops from the baseline engine with $P R_{W}=1$ until $P R_{W}=2$, which might be a practical upper limit for the investigated application. However, if the wave rotor pressure ratio increases beyond this limit, the trend shows that the beneficial effects becomes less while technical problems may increase. With a conceivable wave rotor pressure ratio of 1.8 , the overall efficiency of the baseline cycle increases from $12.6 \%$ to $14.5 \%$ for the enhanced engine. Simultaneously the specific thrust increases from 491 N.s $/ \mathrm{kg}$ to 566 N.s $/ \mathrm{kg}$. The specific fuel consumption of the baseline engine decreases from $0.044 \mathrm{~kg} / \mathrm{kN}$.s to $0.038 \mathrm{~kg} / \mathrm{kN}$.s.

The relative increase of overall efficiency, and specific thrust and relative decrease of specific fuel consumption are shown in Fig. 5. The relative increases of overall efficiency and specific thrust (solid) in Fig. 5 are precisely the same as it is obvious from Eq. (38) and (39) where $u_{a}$ and $h_{P R}$ are constants in the investigation here. Figure 5 indicates an attractive relative performance improvement in overall efficiency and specific thrust of about $15.4 \%$ and $13.3 \%$ in specific fuel consumption using a wave rotor pressure ratio of 1.8 .

A detailed documentation of the other cases is not presented here. Instead, numerical values of relevant cycle data and the performance enhancement are summarized in Table 2. In this table, $\Pi_{C}$ and $\Pi_{T}$ represent the compressor and turbine pressure ratios, respectively and $w_{C}$ denotes the specific work consumed by the compressor. Index "gain" indicates

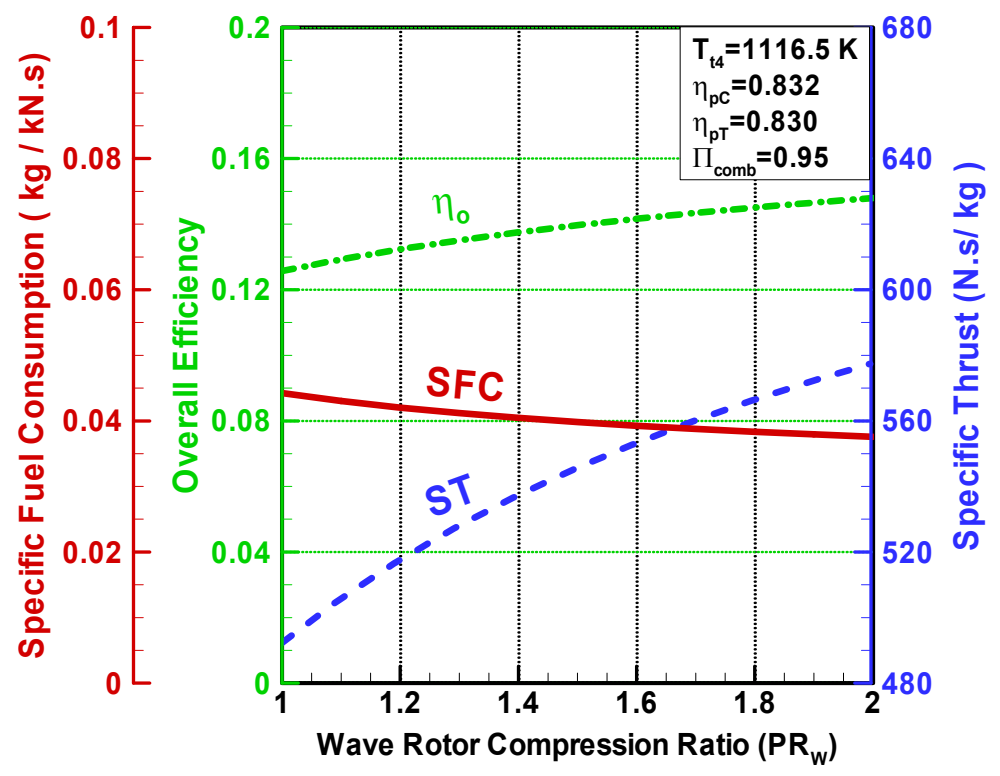

Figure 4: Overall efficiency, specific thrust, and specific fuel consumption of the wave-rotor-topped engines versus wave rotor pressure ratio

American Institute of Aeronautics and Astronautics 


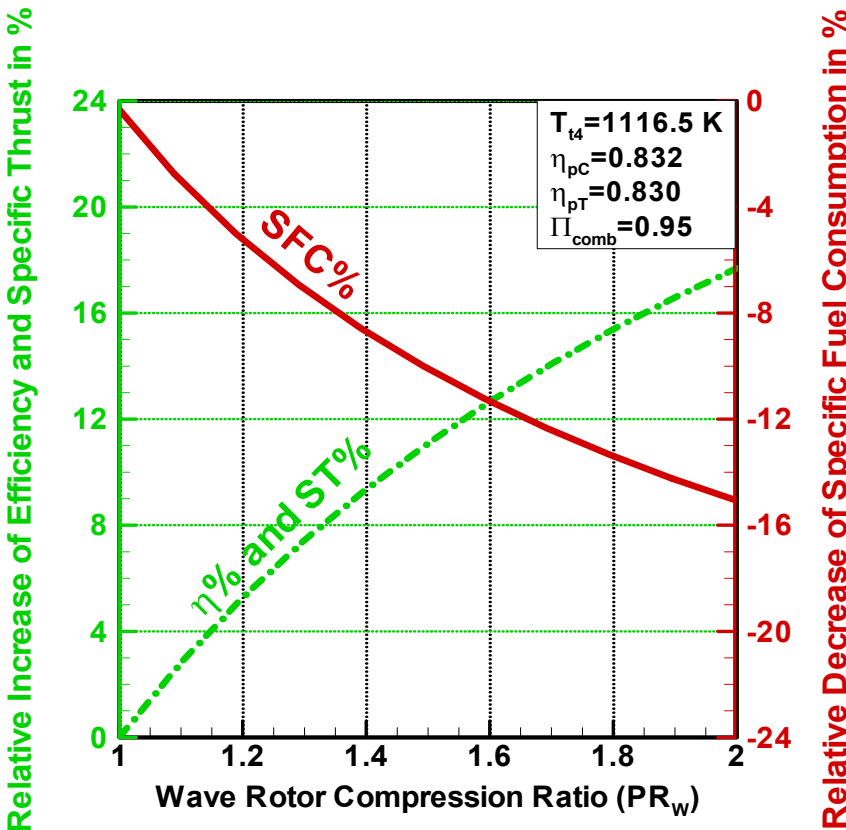

Figure 5: Relative values of overall efficiency, specific thrust, and specific fuel consumption of the wave-rotor-topped engines versus wave rotor pressure ratio

the relative increase of thrust and overall efficiency and decrease of specific fuel consumption. Table 2 shows for Case A perhaps the best combination of high overall efficiency, specific thrust and low specific fuel consumption are achieved. However, Case E provides the lowest value of specific fuel consumption and the highest overall efficiency.

Figure 6 shows a map of the relevant design space for
Cases A, B, and D. Cases $\mathrm{C}$ and $\mathrm{E}$ can not be shown in the same map since in both cases the turbine inlet temperature is less than indicated in the upper right corner of the map. This map allows predicting the performance of the wave-rotor-enhanced engine in terms of overall efficiency (green), specific thrust (blue), and specific fuel consumption (red) for any combination of compressor pressure ratio (abscissa) and wave rotor pressure ratio $P R_{W}$ (parameter labeled in

Table 2: Performance comparison between baseline engines and five cases of wave-rotor-topping with a wave rotor pressure ratio of 1.8

\begin{tabular}{|c|c|c|c|c|c|c|}
\hline & Case A & Case B & Case C & Case D & Case E & \multirow{3}{*}{ Baseline } \\
\hline \multirow{2}{*}{$\begin{array}{c}\text { Same as } \\
\text { baseline } \\
\text { engine }\end{array}$} & $\begin{array}{l}\text { - compressor } \\
\text { - turbine inlet } \\
\text { temp. }\end{array}$ & $\begin{array}{l}\text { - overall press. } \\
\text { ratio } \\
\text { - turbine inlet } \\
\text { temp. }\end{array}$ & - combustor & $\begin{array}{l}\text { - turbine inlet } \\
\text { pressure } \\
\text { - turbine inlet } \\
\text { temp. }\end{array}$ & $\begin{array}{l}\text { - compressor } \\
\text { - combustor end } \\
\text { temp. }\end{array}$ & \\
\hline & $p_{t 1}, T_{t 1}, T_{t 4}$ & $p_{t 2}=p_{t 1 b}, T_{t 4}$ & $\begin{array}{c}p_{t 2}=p_{t 1 b}, T_{t 2}=T_{t 1 b}, \\
T_{t 3}=T_{t 4 b}\end{array}$ & $p_{t 2}=p_{t 1 b}, p_{t 4}, T_{t 4}$ & $p_{t 1}, T_{t 1}, T_{t 3}=T_{t 4 b}$ & \\
\hline$T_{4}[\mathrm{~K}]$ & 1116.5 & 1116.5 & 1056.2 & 1116.5 & 1042.5 & 1116.5 \\
\hline$\Pi_{C}$ & 3.60 & 2.00 & 2.00 & 2.65 & 3.60 & 3.60 \\
\hline$w_{C}[\mathrm{~kJ} / \mathrm{kg}]$ & 140 & 68 & 68 & 100 & 140 & 140 \\
\hline$\Pi_{T}$ & 1.73 & 1.30 & 1.32 & 1.47 & 1.81 & 1.73 \\
\hline$S T[\mathrm{~N} \cdot \mathrm{s} / \mathrm{kg}]$ & 566 & 525 & 493 & 550 & 518 & 491 \\
\hline $\begin{array}{c}S F C \\
{[\mathrm{~kg} / \mathrm{kN} \cdot \mathrm{s}]}\end{array}$ & 0.03833 & 0.04465 & 0.04408 & 0.04119 & 0.03782 & 0.04423 \\
\hline$\eta_{o}$ & 0.145 & 0.125 & 0.126 & 0.135 & 0.147 & 0.126 \\
\hline$(S T)_{\text {gain }}[\%]$ & 15.4 & 7.1 & 0.46 & 12.1 & 5.6 & \\
\hline$(S F C)_{\text {gain }}[\%]$ & 13.3 & 0.1 & -0.3 & 6.9 & 14.5 & \\
\hline$\left(\eta_{o}\right)_{\text {gain }}[\%]$ & 15.4 & -0.9 & 0.3 & 7.4 & 17.0 & \\
\hline
\end{tabular}

American Institute of Aeronautics and Astronautics 


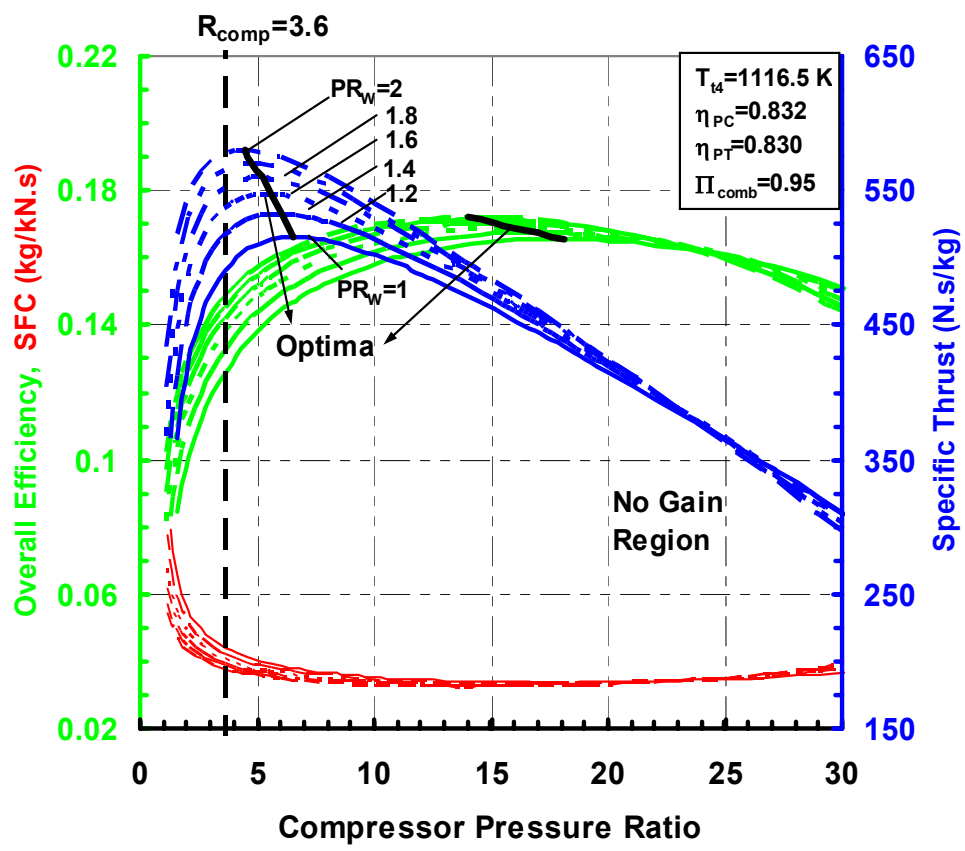

Figure 6: Maps of overall thermal efficiency and specific work for wave-rotor-topping of gas turbines

black). The optimum compressor pressure ratio points for highest overall efficiency and specific thrust at each achievable wave rotor pressure ratio are connected by black solid lines. As discussed above, the optima for specific fuel consumption are found at the same combination of $R$ and $P R_{W}$ as the optima of the overall efficiency.

The performance map is general. The only specific parameters are indicated in the upper right corner of the map. They are turbine inlet temperature, polytropic efficiencies of compressor and turbine, and the pressure loss across the combustor corresponding to the baseline engine. Such a map is not only useful to explore the possible enhancement of already existing baseline engines, it also serves very well for selecting a design point or region when designing a new wave-rotortopped engine. For instance, starting from the performance point of the baseline engine, the performance values for Case A are found by moving vertically upwards (along the dashed line representing the baseline compressor pressure ratio of 3.6) until the corresponding performance curve of the expected wave rotor pressure ratio is crossed.

The results indicate that for every compressor pressure ratio in the shown design space, the performance of the topped engine is always higher than that of the corresponding baseline engine with the same compressor pressure ratio (Case A consideration). However, for higher compressor pressure ratios the benefit of using a wave rotor becomes less. In fact, for compressor pressure ratios greater than 20 , almost no benefit can be obtained. The benefit is the greatest for lower compressor pressure ratios. This clearly favors the wave-rotor-topping for small gas turbines with low compressor pressure ratios.

\section{CONCLUSIONS}

The present investigation predicts an attractive performance enhancement by implementing a four-port wave-rotor in a small turbojet engine. Five different cases of implementing the wave rotor in a baseline engine are investigated. The commonly discussed Case A appears to be the most attractive since the baseline compressor and turbine may remain unchanged, and still almost the best performance enhancement is achieved. However, the combustor would work under higher pressure and with higher combustion end temperature, possibly requiring an enhanced structure and fuel injection system. Other cases with unchanged overall pressure ratio (Cases $\mathrm{B}$ and $\mathrm{C}$ ), with unchanged combustion end temperature (Cases $\mathrm{C}$ and $\mathrm{E}$ ) or unmodified turbine inlet conditions (Case D) are investigated as well. Case D is especially attractive if heat recovery is anticipated, which would enhance the performance even more.

\section{REFERENCES}

[1] Zauner, E., Chyou, Y. P., Walraven, F. and Althaus, R., 1993, "Gas Turbine Topping Stage Based on Energy Exchangers: Process and Performance," ASME Paper 93-GT-58.

[2] Meyer, A., 1947, "Recent Developments in Gas Turbines," Journal of Mechanical Engineering, 69, No. 4, pp. 273-277.

[3] Seippel, C., 1946, "Pressure Exchanger," U.S. Patent 2,399,394. 
[4] Weber, H. E., 1995, Shock Wave Engine Design, John Wiley and Sons, New York.

[5] Mayer, A., Oda, J., Kato, K., Haase, W. and Fried, R., 1989, "Extruded Ceramic - A New Technology for the Comprex ${ }^{\circledR}$ Rotor," SAE Paper 890453.

[6] Zehnder, G., Mayer, A. and Mathews, L.,1989, “The Free Running Comprex®," SAE Paper 890452.

[7] Taussig, R. T., 1984, "Wave Rotor Turbofan Engines for Aircraft," Winter Annual Meeting of the $A S M E$, edited by Sladky, J. F., Machinery for Direct Fluid-Fluid Energy Exchange, AD-07, pp. 9-45.

[8] Shreeve, R. P., Mathur, A., 1985, Proceeding ONR/NAVAIR Wave Rotor Research and Technology Workshop, Report NPS-67-85-008, Naval Postgraduate School, Monterey, CA.

[9] Paxson, D. E., 1995, "Comparison Between Numerically Modeled and Experimentally Measured Wave-Rotor Loss Mechanism," Journal of Propulsion and Power, 11, No. 5, pp. 908-914. See also NASA TM-106279.

[10] Paxson, D. E., 1996, "Numerical Simulation of Dynamic Wave Rotor Performance," Journal of Propulsion and Power, 12, No. 5, pp. 949-957.

[11] Paxson, D. E., Nalim, M. R., 1999, "Modified Through-Flow Wave-Rotor Cycle with Combustor Bypass Ducts" Journal of Propulsion and Power, 15, No. 3, pp. 462-467.

[12] Welch, G. E., Jones, S. M. and Paxson, D. E., 1997, "Wave Rotor-Enhanced Gas Turbine Engines," Journal of Engineering for Gas Turbines and Power, 119, No. 2, pp. 469-477.

[13] Welch, G. E., 1997, "Macroscopic Balance Model for Wave Rotors," Journal of Propulsion and Power, 13, No. 4, pp. 508-516.

[14] Welch, G. E., 1997, “Two-Dimensional Computational Model for Wave Rotor Flow Dynamics," Journal Engineering for Gas Turbines and Power, 119, No. 4, pp. 978-985.

[15] Wilson, J., 1998, "An Experimental Determination of Loses in a Three-Port Wave Rotor," Journal of Engineering for Gas Turbines and Power, 120, pp. 833842. See also ASME Paper 96-GT-117, 1996.

[16] Wilson, J., Paxson, D. E., 1996, "Wave Rotor Optimization for Gas Turbine Topping Cycles," Journal of Propulsion and Power, 12, No. 4, pp. 778-785. See also SAE Paper 951411, 1995, and NASA TM 106951. [17] Welch, G. E., 2000, "Overview of Wave-Rotor Technology for Gas Turbine Engine Topping Cycles," Novel Aero Propulsion Systems International Symposium, The Institution of Mechanical Engineers, pp. 2-17.

[18] Wilson, J. and Paxson, D. E., 1993, "Jet Engine Performance Enhancement Through Use of a WaveRotor Topping Cycle," NASA TM-4486.
[19] Paxson, D. E., 1993, “A Comparison Between Numerically Modeled and Experimentally Measured Loss Mechanisms in Wave Rotors," AIAA Paper 932522.

[20] Welch, G. E., Jones, S. M. and Paxson, D. E., 1995, "Wave Rotor-Enhanced Gas Turbine Engines," AIAA Paper 95-2799. See also NASA TM-106998, and ARL-TR-806.

[21] Welch, G. E., Chima, R. V., 1993, "TwoDimensional CFD Modeling of Wave Rotor Flow Dynamics," AIAA Paper 93-3318. Also see NASA TM-106261.

[22] Welch, G. E., 1996, "Macroscopic Balance Model for Wave Rotors," AIAA Paper 96-0243. See also NASA TM-107114, and ARL-TR-925.

[23] Welch, G. E., 1996, “Two-Dimensional Computational Model for Wave Rotor Flow Dynamics," ASME Paper 96-GT-550.

[24] Snyder, P. H., Fish, R. E., 1996, "Assessment of a Wave Rotor Topped Demonstrator Gas Turbine Engine Concept," ASME Paper 96-GT-41.

[25] Snyder, P. H., 1996, "Wave Rotor Demonstrator Engine Assessment," NASA CR-198496.

[26] Fatsis A, Ribaud Y., 1997, "Numerical Analysis of the Unsteady Flow Inside Wave Rotors Applied to Air Breathing Engines," 13th International Symposium on Airbreathing Engines .

[27] Fatsis A, Ribaud Y., 1998, "Preliminary Analysis of the Flow Inside a Three-Port Wave Rotor by Means of a Numerical Model," Aerospace Science and Technology, 2, No. 5, pp. 289-300.

[28] Fatsis A, Ribaud Y., 1999, "Thermodynamic Analysis of Gas Turbines Topped with Wave Rotors," Aerospace Science and Technology, 3, No. 5, pp. 293299.

[29] Jones, S. M., Welch, G. E., 1996, "Performance Benefits for Wave Rotor-Topped Gas Turbine Engines," ASME Paper 96-GT-075.

[30] Akbari, P., Müller, N., 2003, "Performance Improvement of Small Gas Turbines Through Use of Wave Rotor Topping Cycles," 2003 International ASME/IGTI Turbo Exposition, ASME Paper GT200338772.

[31] Akbari, P., Müller, N., 2003, "Preliminary Design Procedure for Gas Turbine Topping Reverse-Flow Wave Rotors," 2003 International Gas Turbine Congress Tokyo, Paper IGTC2003-ABS-129.

[32] Akbari, P., Müller, N., 2003, "Gas Dynamic Design Analyses of Charging Zone for Reverse-Flow Pressure Wave Superchargers," 2003 ASME Spring Technical Conference, Salzburg, Austria, ASME Paper ICES2003-690.

[33] Mattingly, J. D., 1996, Elements of Gas Turbine Propulsion, McGraw-Hill, International Editions. 